\title{
The use of geographic information system as a tool for schistosomiasis surveillance in the province of Davao del Norte, the Philippines
}

\author{
Vicente Y. Belizario, ${ }^{1}$ John Paul Caesar R. delos Trinos, ${ }^{1,2}$ Berne Silawan, ${ }^{3}$ \\ Chiqui M. de Veyra, ${ }^{1}$ Agapito B. Hornido, ${ }^{4}$ Hansel Amoguis, ${ }^{5}$ Dominic Basalo, ${ }^{6}$ \\ Cherry Dema-ala, ${ }^{7}$ Irenn Mantilla, ${ }^{5}$ Rosele Layan ${ }^{4}$
}

${ }^{1}$ College of Public Health, University of the Philippines Manila, the Philippines; ${ }^{2}$ School of Public Health and Community Medicine, University of New South Wales, Sydney, Australia; ${ }^{3}$ Davao del Norte Provincial Planning and Development Office, Government Center, Tagum City; ${ }^{4}$ Davao del Norte Provincial Health Office, Government Center, Tagum City; ${ }^{5}$ Department of Health Regional Office XI, Davao City; ${ }^{6}$ Rural Health Unit, Carmen; ${ }^{7}$ Rural Health Unit, Braulio Dujali, the Philippines

\begin{abstract}
Schistosomiasis (SCH) in The Philippines is caused by Schistosoma japonicum and remains endemic in 28 provinces in 12 regions. Effective $\mathrm{SCH}$ control requires describing areas at risk where control efforts may be focused. This study aims at demonstrating the utility of geographical information system (GIS) as a tool for SCH surveillance in the province of Davao del Norte. Qualitative and quantitative data on $\mathrm{SCH}$ determinants, obtained from local government offices, partner agencies and institutions, were standardised, formatted and incorporated into a GIS map. Atrisk areas are described in terms of determinants and (variables),
\end{abstract}

Correspondence: Vicente Y. Belizario, Department of Parasitology, Lara Hall, College of Public Health, University of the Philippines Manila, 625 Pedro Gil St, Ermita, Manila, 1000 Metro Manila, the Philippines.

Tel: +632-523-5929 loc 142 .

E-mail: vbelizar@yahoo.com

Key words: Schistosomiasis; Davao del Norte; The Philippines; Spatial information technologies; Geographic information systems.

Acknowledgments: the researchers would like to acknowledge the partner institutions, such as the DOH RO XI and the LGUs of Davao del Norte, as well as Dr. Gracita Berguia and Ms. Marie Cris Modequillo of DOH XI and Ms. Maureen Reyes, for their valuable contributions which made this study possible.

Received for publication: 2 January 2017.

Revision received: 20 May 2017.

Accepted for publication: 21 May 2017.

(C) Copyright V.Y. Belizario et al., 2017

Licensee PAGEPress, Italy

Geospatial Health 2017; 12:540

doi:10.4081/gh.2017.540

This article is distributed under the terms of the Creative Commons Attribution Noncommercial License (CC BY-NC 4.0) which permits any noncommercial use, distribution, and reproduction in any medium, provided the original author(s) and source are credited. which included geography and climate (topography, temperature and flood-prone areas), agriculture (irrigation and land use), poverty (percentage of households with income below the poverty threshold), sanitation level (percentage of households with sanitary toilets), intermediate and reservoir hosts (presence of snail colonies and reservoir hosts) as well as prevalence and treatment coverage. Endemic villages (barangays) were generally found to be located in flood-prone areas in the lowlands near major rivers. New Corella has the highest poverty index among the $\mathrm{SCH}$-endemic areas studied as well as the highest number of confirmed snail colonies. Among known endemic localities in Davao del Norte, Tagum City was found to be the only city meeting the poverty index target of $<16.6 \%$. Clustering of SCH cases were reported in six barangays ranging from $0.48 \%$ (8 out of 1,655$)$ in Braulio Dujali to $2 \%(25$ out of 1,405) in Asuncion. This study demonstrates the utility of GIS in predicting and assessing SCH risk, which allows prioritisation and allocation of control resources and delivery of services in areas at the highest risk for $\mathrm{SCH}$.

\section{Introduction}

Neglected tropical diseases (NTDs) are a diverse group of communicable diseases that prevail in areas characterised by tropical and subtropical conditions. These diseases affect more than one billion people, mostly those living in impoverished conditions without adequate sanitation and with respect to schistosomiasis $(\mathrm{SCH})$ in close contact with its snail intermediate hosts and in Asia also with reservoir hosts, such as livestock and some wild animals (WHO, 2016). Ending epidemics of NTDs by 2030 is included as a target of the Sustainable Development Goals (SDGs) (United Nations, 2016).

$\mathrm{SCH}$, a debilitating, potentially fatal NTD, with considerable health and economic effects (King and Dangerfield-Cha, 2008; WHO, 2016), is targeted for elimination by 2020 (WHO, 2012). According to the Department of Health (DOH) in The Philippines, $\mathrm{SCH}$ is endemic in 12 regions affecting 28 provinces, where it is caused by Schistosoma japonicum and transmitted by the freshwater snail Oncomelania hupensis quadrasi (Philippines Department of Health, 2015). The SCH Control and Elimination Program (SCEP), implemented by the $\mathrm{DOH}$, aims to reduce prevalence by $50 \%$ and envisions SCH elimination in all endemic areas. This 
will be achieved through mass drug administration (MDA) of praziquantel and control of infection and transmission by surveillance as well as advocacy and health promotion (Philippines Department of Health, 2007). In support of the national control programme, the University of the Philippines (UP) Manila has implemented the War on Worms (WOW) Campaign to provide technical support to $\mathrm{DOH}$ and local government units (LGUs) for a more effective control of SCH and also intestinal helminthiases.

Surveillance of SCH plays a crucial role in the formulation and implementation of effective strategies for disease control and prevention. The use of spatial information technologies (SIT), which include geographical information systems (GIS), may serve as an innovative approach in SCH surveillance. The application of GIS in mapping temporal and spatial distribution of S. japonicum and assessing the risk of infection has been demonstrated in China (Wang and Zhuang, 2015), Africa (Manyangadze et al., 2015) and Brazil (Guimaraes et al., 2008). The application of GIS in SCH prevention and control in The Philippines, however, remains limited (Leonardo et al., 2007). This study aimed to demonstrate the utility of GIS as a tool for surveillance to guide programme policy and planning for SCH control in the Philippine province of Davao del Norte on Mindanao in the South of the country.

\section{Materials and Methods}

\section{Study site}

Davao del Norte, a province in Region XI (Davao Region) of The Philippines, is bordered by Agusan del Sur in the North, Davao Gulf and Davao City in the South, Compostela Valley in the East, and Davao del Sur in the West. It has a land area of 3,463 $\mathrm{km}^{2}$, which stretches from latitude $6^{\circ} 05^{\prime} 00^{\prime \prime}$ to $8^{\circ} 00^{\prime} 00^{\prime \prime}$ and longitude from $125^{\circ} 018^{\prime} 25^{\prime \prime}$ to $125^{\circ} 055^{\prime} 75^{\prime \prime}$ (Davao del Norte Provincial Environmental and Natural Resources Office, 2016) and is composed of eight municipalities and three component cities (Figure 1). Six municipalities (Asuncion, Braulio Dujali, Carmen, Kapalong, New Corella and Sto. Tomas) and one city (Tagum
City) are known as SCH-endemic (Philippines Department of Health, 2009). Davao del Norte has a total population of 945,764 , the highest population among the provinces in Davao Region (Philippine Statistics Authority, 2013). The province was selected as the study site based on availability of data and endemicity of $\mathrm{SCH}$, as well as active participation of and partnership with local stakeholders, such as the DOH Regional Office (RO) XI and LGUs. Davao del Norte is also one of the sites where the WOW Campaign is being implemented since 2012 .

\section{Data collection and processing}

$\mathrm{SCH}$ determinants and variables were identified through review of the literature. Discussions facilitated by the WOW

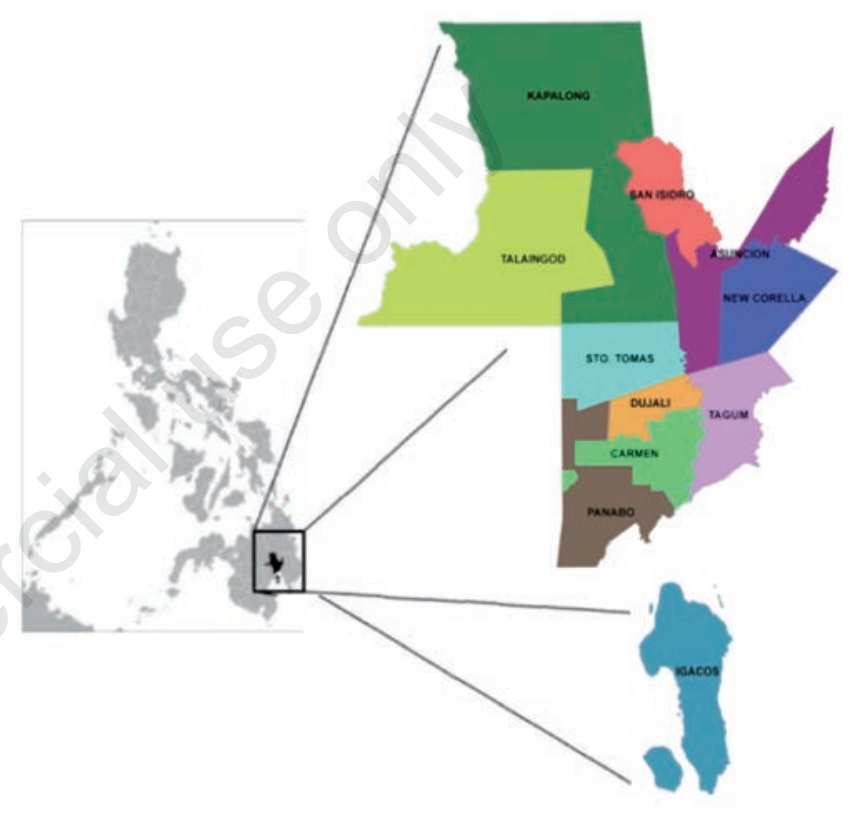

Figure 1. The municipalities and cities of Davao del Norte.

Table 1. Determinants, variables and ecological conditions supporting schistosomiasis.

\begin{tabular}{|c|c|c|c|c|}
\hline Determinant & Variable & Source and time of collection & Favourable SCH condition & References \\
\hline Geography and climate & $\begin{array}{c}\text { Topography } \\
\text { Temperature } \\
\text { Flood-prone areas }\end{array}$ & $\begin{array}{c}\text { PPDO (2015) } \\
\text { WorldClim } \\
\text { (2000; http://www.worldclim.org) } \\
\text { Mines and Geosciences } \\
\text { Bureau Region XI (2014) }\end{array}$ & $\begin{array}{l}\text { Presence of freshwater bodies } \\
\text { Temperatures ranging } \\
\text { from } 15.4-30^{\circ} \mathrm{C} \\
\text { Presence of flood-prone areas* }\end{array}$ & $\begin{array}{l}\text { Grimes et al. (2015) } \\
\text { Zhou et al. 2009; } \\
\text { Yang et al. (2006) } \\
\text { Katanha and } \\
\text { Masocha (2014) }\end{array}$ \\
\hline Agriculture & $\begin{array}{l}\text { Irrigation } \\
\text { Land use }\end{array}$ & $\begin{array}{l}\text { PAGRO and NIA (2014) } \\
\text { PAGRO and PPDO (2013) }\end{array}$ & $\begin{array}{l}\text { Presence of irrigation canals and dams } \\
\text { Lands used for vegetation }\end{array}$ & $\begin{array}{l}\text { McManus et al. (2010) } \\
\text { Zhang et al. (2004) }\end{array}$ \\
\hline Poverty & Poverty index* & PSWDO (2012) & High poverty index & NEDA (2013) \\
\hline Sanitation & Sanitary index ${ }^{\S}$ & PHO (2014) & Low sanitary index ${ }^{\wedge}$ & DOH (2010) \\
\hline Intermediate snail host & Presence of snail colonies & PHO (2014) & Presence of snail colonies & Not applicable \\
\hline Animal reservoir hosts & Presence of reservoir host & PVO (2014) & Presence of animal reservoirs & Not applicable \\
\hline $\mathrm{SCH}$ & Prevalence level & PHO and UP (2012 and 2014) & SCH prevalence $\geq 1 \%$ & WHO (2012) \\
\hline Treatment & MDA coverage rate & PHO (2013-2015) & MDA coverage rates $<75 \%$ & WHO (2012) \\
\hline
\end{tabular}

SCH, schistosomiasis; PPDO, Provincial Planning and Development Office; PAGRO, Provincial Agriculture Office; NIA, National Irrigation Administration; PSWDO, Provincial Social Welfare and Development Office; PHO, Provincial Health Office; PVO, Provincial Veterinarian Office; UP, University of the Philippines Manila; NEDA, National Economic and Development Authority. MDA, mass drug distribution. *Defined as areas which experienced flooding as of 2014 ; ${ }^{\circ}$ percentage of households with income below the poverty threshold; \#defined as municipalities having a $\geq 16.6 \%$ percentage of households with under-threshold incomes, which is the national target under the 2011-2016 Philippine Development Plan; ${ }^{\circledR}$ percentage of households with sanitary toilets; ^ defined as municipalities with households having a percentage of sanitary toilets lower than the $95 \%$ national coverage target (DOH, 2010). 
Project Team and participated by key staff of DOH RO XI and Davao del Norte Provincial Health Office (PHO) were conducted to identify data sources and to collect information on known $\mathrm{SCH}$ determinants. The latest qualitative and quantitative data on $\mathrm{SCH}$ determinants were requested and obtained from local government offices, agencies, and partner institutions (Table 1). Municipalities were classified based on the presence of conditions favourable for $\mathrm{SCH}$ transmission.

\section{Geography and climate}

Data on topography, namely, bodies of water, and municipal and barangay boundaries, were retrieved from the GIS database of Davao del Norte Provincial Planning and Development Office (PPDO). Data on bodies of water, which included rivers and creeks, were digitalised using satellite imagery. Data on temperature were obtained from the WorldClim's global climate dataset (Hijman et al., 2015; WorldClim-Global Climate Data, 2017) and limited to available records for the period of 1950-2000. Data on flood-prone areas were obtained from the Mines and Geosciences Bureau - Region XI. Data obtained were culled, added as mosaic, clipped to national bounding box and re-projected to local coordinates. A 1-km raster resolution was used.

\section{Agriculture}

Data on agriculture, which included types of irrigation and land use (e.g. types of crops planted) for the year 2013, were obtained from the Davao del Norte Provincial Agriculture Office (PAGRO) and supplemented by PPDO.

\section{Poverty}

The poverty index, defined as the percentage of households with per capita annual income less than the per capita poverty threshold per municipality for the year 2012 (PHP 18,935.00 or USD 378.70, USD $1.00=$ PHP 50.00) based on small-area estimates, was obtained from the Provincial Social Welfare and Development Office (PSWDO). The municipalities were classified as having a poverty index either (1) greater than or equal to, or (2) less than the national index of $\leq 16.6 \%$ (National Economic and Development Authority, 2013).

\section{Sanitation}

The percentage of households with sanitary toilets per village (barangay) in the province for 2014 was obtained from the PHO. The municipalities were classified as having a percentage of households with sanitary toilets either (1) greater than or equal to, or (2) less than the national target for coverage of $95 \%$ (Philippines Department of Health, 2010a, 2010b).

\section{Snail colonies}

Data on distribution of snail colonies per barangay were obtained from the results of the malacological survey conducted by the designated staff of PHO. The locations of snail sites were geotagged using GPS by the designated PHO staff. Data on snail colonies were limited to the usual areas where DOH RO XI or Davao del Norte PHO routinely conducts malacological surveys. Identified snail colonies (available up to the year 2014) were marked on the GIS map generated.

\section{Reservoir hosts}

Data on distribution of animal reservoir hosts per barangay for the year 2014 were requested from the Provincial Veterinary Office (PVO).

\section{Disease prevalence}

Data for SCH prevalence were obtained from the PHO, specifically from the results of focal parasitological survey in Davao del Norte, a cross-sectional survey conducted by DOH among 5-65 years old residents in the SCH-endemic areas in 2014. Supplementary data on SCH prevalence were obtained from the results of the sentinel surveillance in school-age children (SAC) conducted by the UP Manila in the municipalities of Carmen and Sto. Tomas in 2012 and 2014 as part of the monitoring and evaluation of the WOW Campaign. Both parasitological surveys used the Kato-Katz technique (WHO, 1994) for stool examination. Prevalence data per municipality were compared with the WHO target of $<1 \%$ for $\mathrm{SCH}$ prevalence (WHO, 2012). Municipalities were classified as having $\mathrm{SCH}$ prevalence either (1) greater than or equal to, the WHO target or (2) less than this target.

\section{Mass drug administration coverage}

The MDA coverage rates for SCH for the years 2013-2015 were obtained from the PHO. The average MDA coverage rate for the three years for each municipality was compared with the target coverage of WHO of at least $75 \%$ of the population (WHO, 2012). Coverage rates were disaggregated into barangays. Municipalities were classified as having average MDA coverage rate of either (1) greater than or equal to the WHO target or (2) less than this target.

\section{Intersectoral workshops on the development of a geo- graphical information system map}

An initial intersectoral workshop, attended by representatives from DOH RO XI, Davao del Norte PHO, PPDO, PAGRO, PSWDO, PVO, and UP Manila was conducted in December 2014. Data on the SCH determinants and variables/conditions were presented and a prototype GIS map was developed. Prior to data entry in the GIS, the data were standardised following the specifications of ArcGIS, version 10.2.1 (ESRI Inc., Redlands, CA, USA). Standardised data were incorporated into the GIS map either by digitising or by tracing the location, path, or boundary of geographic features. Each data layer in the GIS map was made to correspond to a unique $\mathrm{SCH}$ determinant. The layers were stacked to highlight patterns and trends. Colours and symbols were used to allow distinction of attributes. A follow-up intersectoral workshop was conducted in July 2015 to present the pre-final GIS maps to the stakeholders for additional inputs. The final GIS maps were approved by the stakeholders and retained in the GIS database of the Davao del Norte PPDO for use in future planning and policy formulations.

\section{Results}

\section{Geography and climate}

Davao del Norte has mountainous areas on the western part of the municipalities of Talaingod and San Isidro and wide plains in central lowland areas. All of the known SCH-endemic municipalities/cities, namely, Asuncion, Braulio Dujali, Carmen, Kapalong, New Corella, Sto. Tomas, and Tagum City are situated in the lowlands and adjacent to each other. Major rivers in the province 
include Libuganon River, which flows from Kapalong through Asuncion, Tagum City, Braulio Dujali, and Carmen, and Tuganay River which flows from Sto. Tomas through Braulio Dujali and Carmen. All major rivers pass through the barangays of the known $\mathrm{SCH}$-endemic municipalities. Municipalities not known to be $\mathrm{SCH}$-endemic, on the other hand, are mostly mountainous and have barangays that are not adjacent to major waterways. An exception is Panabo City, which is not a known endemic area, but is in a lowland area and includes barangays adjacent to waterways.

Flood-prone areas are concentrated in lowland areas in the South and south-eastern parts of the province. These areas are also located around major rivers flowing through the barangays of the known endemic municipalities of Braulio Dujali, Carmen, and portions of Tagum City. There is neither a major river nor a floodprone area in the Island Garden City of Samal (IGACOS) (Figure 2). In Davao del Norte, temperatures range from $19.3^{\circ} \mathrm{C}$ in the western mountainous areas to $27.2^{\circ} \mathrm{C}$ in the central lowlands. IGA$\mathrm{COS}$, on the other hand, has moderate to high temperatures despite its semi-mountainous topography. SCH-endemic municipalities have relatively high temperatures except in the north-eastern part of New Corella, which has higher elevation with moderate temperatures (Figure 3).

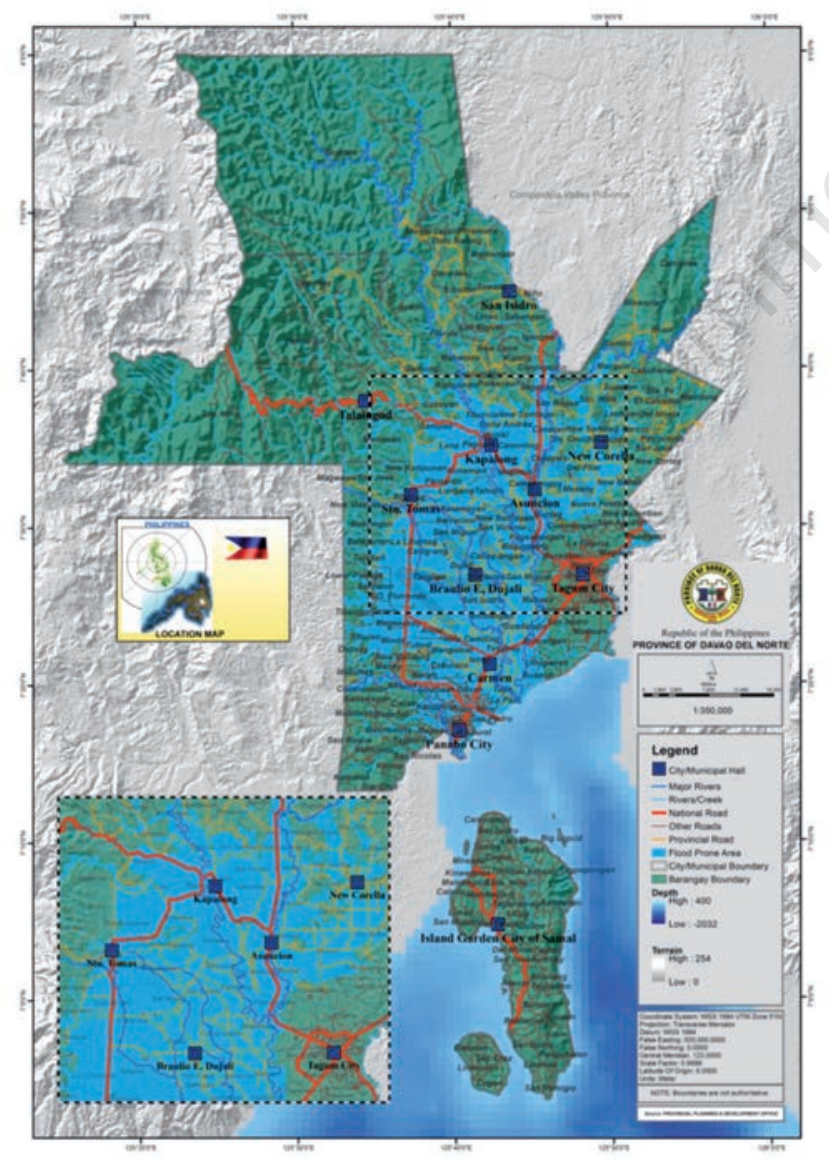

Figure 2. The topography, i.e., municipal and barangay boundaries, major roads and highways, terrain, major rivers and creeks as well as flood-prone areas in Davao del Norte.

\section{Agriculture}

Most of the areas in the mountainous part of Davao del Norte are grasslands, shrublands or forests, particularly on the northwestern part of the province. Lowland areas, on the other hand, are generally used for plantations of banana, cacao and other major crops, such as rice and corn. Tagum City and Panabo City are composed mostly of residential and commercial areas. Majority of coconut plantations are found in IGACOS. Rice fields are located in flood-prone areas. In Tagum City, portions of residential and commercial areas are located near flood-prone areas (Figure 4). Neither the PAGRO nor the National Irrigation Administration (NIA) was able to provide the data on geographical locations of irrigation canals in Davao del Norte.

\section{Poverty and sanitation}

Talaingod, a municipality not known as $\mathrm{SCH}$-endemic, was seen having the highest poverty index $(68.8 \%)$ in the province. Among the $\mathrm{SCH}$-endemic municipalities in the province, New Corella showed the highest poverty index (41.6\%), while the lowest was in Tagum City (13.80\%). Among the known endemic localities, Tagum City is the only city meeting the national poverty index target of $\leq 16.6 \%$.

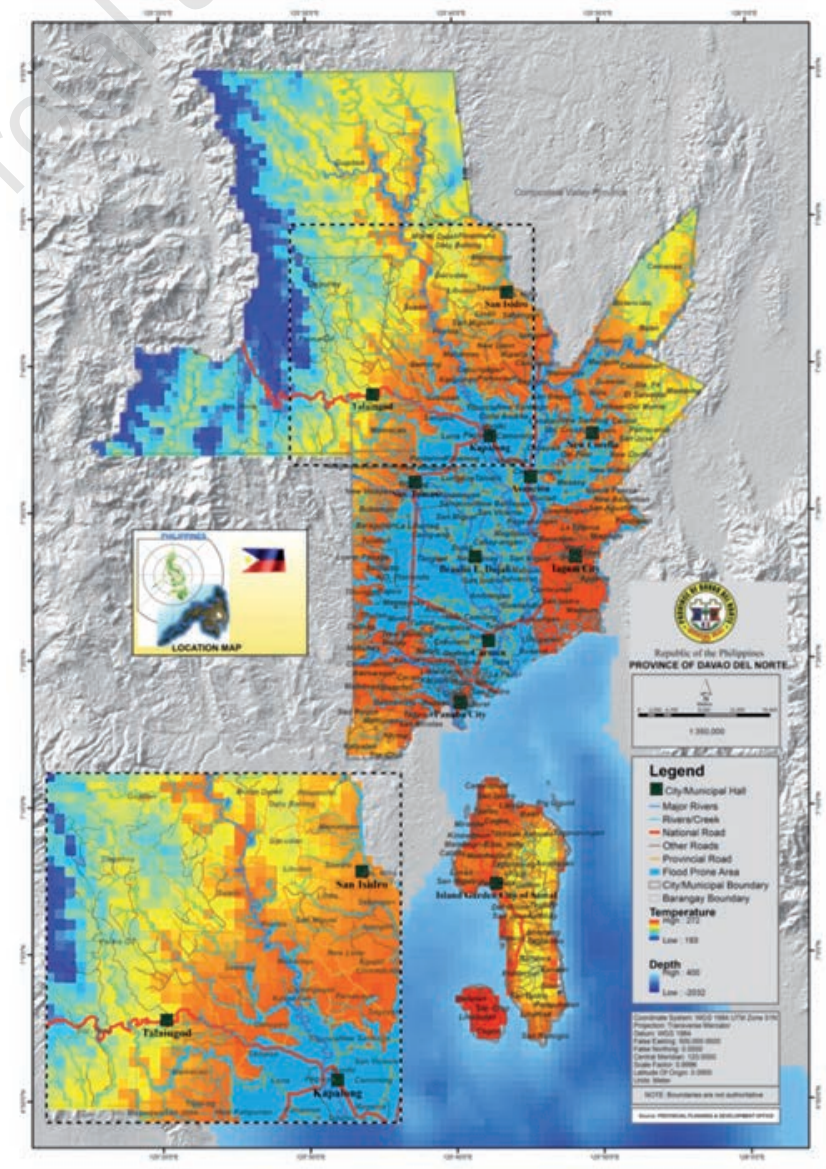

Figure 3. The topography of Davao del Norte overlaid with temperature data. 
Davao del Norte was found to have the highest coverage of sanitary toilets in the Davao Region (90\%). For the province as a whole, New Corella had the highest coverage (98\%), while Tagum City had the lowest (89\%). Among the municipalities where data on sanitation exist, Braulio Dujali, Kapalong, and Tagum City did not meet the toilet coverage target. It is important to note, however, that all municipalities and cities had barangays that do not meet the coverage target of sanitary toilets (Figure 5).

\section{Intermediate snail host}

Most of the identified snail colonies were found in barangays in the municipality of New Corella, while the rest were located in barangays belonging to the municipalities Kapalong, Braulio Dujali and Carmen. Snail colonies in the province were mostly found in areas with high temperature, in flood-prone areas and in areas with a poverty index above the national target and with sanitary toilet coverage below (Figure 6). Available data on snail colonies, however, are only limited to the usual areas where malacological surveys are conducted by DOH RO XI and Davao del Norte PHO, while there might be many others that remain unsampled.

\section{Animal reservoir hosts}

The PVO did not have data on distribution of animal reservoir hosts in the province.

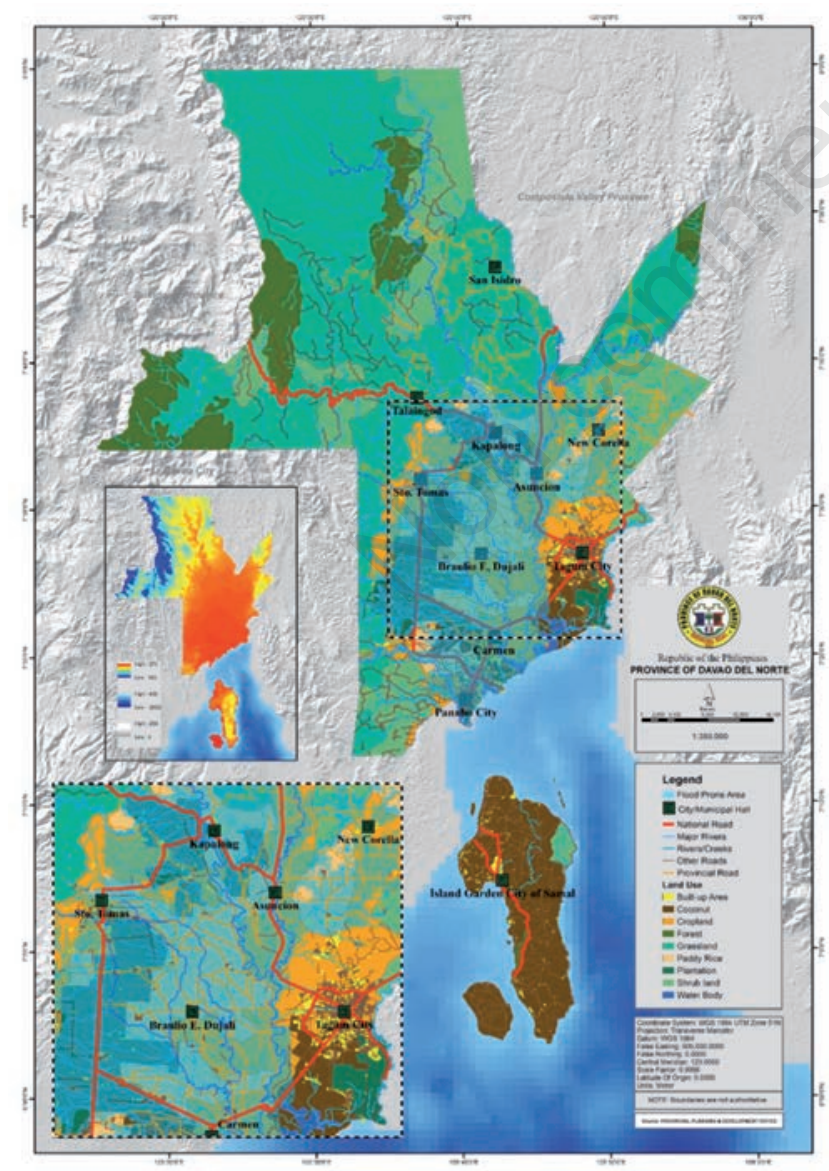

Figure 4. Land use in Davao del Norte overlaid with topography and temperature data.

\section{Disease prevalence}

$\mathrm{SCH}$ prevalence levels of $>1 \%$ were found in the barangays of the municipalities of Asuncion, New Corella, Kapalong, Braulio Dujali, Carmen, Sto. Tomas, and Tagum City. SCH cases were found in barangays with identified and confirmed snail sites and colonies. In the barangays Cabaywa in Asuncion and Pagsabangan in Tagum City, where the highest SCH prevalence levels were found, however, there was no known snail colony. Incidentally, these areas are flood-prone with $\mathrm{SCH}$ prevalence rates ranging from $0.48 \%$ (8 out of 1,655$)$ in Braulio Dujali to $1.8 \%$ (25 out of 1,405$)$ in Asuncion (Figure 7).

\section{Mass drug administration coverage}

Tagum City has the highest praziquentel MDA coverage rate in the period 2013-2015 (79.3\%) making it the only city in the province meeting the WHO target. Asuncion, on the other hand, has the lowest MDA coverage rate for SCH (50.8\%) (Figure 8). Six out of the seven $\mathrm{SCH}-\mathrm{endemic}$ municipalities and the city failed to meet the WHO target for MDA coverage.

\section{Schistosomiasis determinants and variables considered}

Figure 9 shows the data layers referring to $\mathrm{SCH}$ determinants, health facilities, as well as schools in Davao del Norte. All SCH cases were reported in flood-prone areas and have temperatures between $15.9^{\circ} \mathrm{C}$ and $30.0^{\circ} \mathrm{C}$. All of the SCH-endemic municipalities have

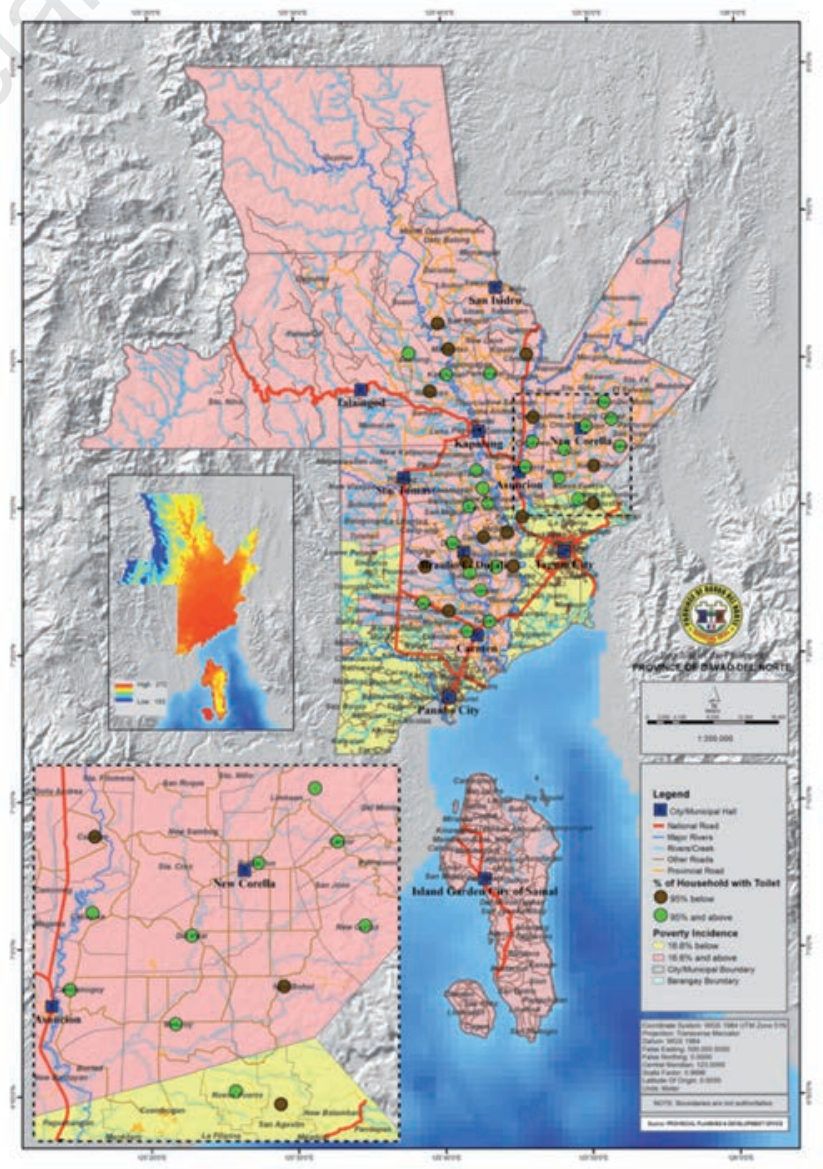

Figure 5. Poverty level and sanitation of Davao del Norte overlaid with topography and temperature data. 
areas used for vegetation. Among the SCH-endemic municipalities and city, only Tagum City has poverty index meeting the national target. Three out of the six SCH-endemic municipalities, namely Braulio Dujali, Kapalong, and Tagum City, have coverage of sanitary toilets not meeting the target. Except for Cabaywa in Asuncion and Pagsabangan in Tagum City, all SCH cases were reported in municipalities where snail colonies were found. There were 10 barangays (Cabaywa in Asuncion; Pagsabangan in Tagum City; Poblacion, Mesaoy, and Del Pilar in New Corella; Mabaus in Carmen; San Vicente and Esperanza in Sto. Tomas; and Mabantao and Florida in Kapalong) with $>1 \%$ SCH prevalence and they are all traversed by waterways. On the other hand, New Casay in Braulio Dujali is a $\mathrm{SCH}$-endemic barangay, which is also prone to flooding. Among the barangays with data on $\mathrm{SCH}, 26$ barangays which have $<1 \% \mathrm{SCH}$ prevalence are either traversed by waterways or are prone to flooding.

Table 2 shows the presence of favourable conditions of $\mathrm{SCH}$ determinants for disease transmission in municipalities in Davao del Norte. Out of eight flood-prone municipalities, only Panabo City is not classified as SCH-endemic. All of the municipalities have suitable temperatures for $S$. japonicum development. Seven out of eight municipalities that use portions of its land for vegetation, are endemic for $\mathrm{SCH}$. Among the SCH-endemic municipalities and the city, only Tagum City showed poverty index meeting the national target. Out of the seven $\mathrm{SCH}$-endemic areas, only six municipalities had confirmed snail sites and colonies.

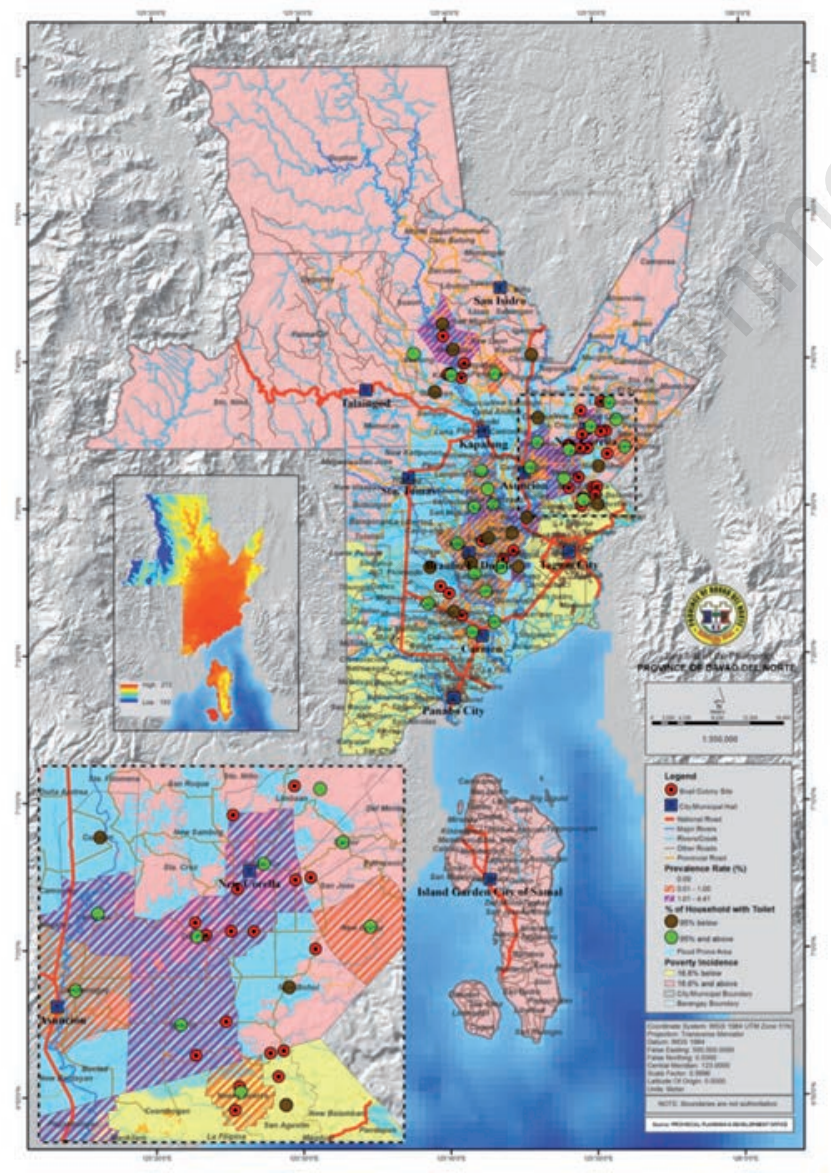

Figure 6. The distribution of snail colonies in Davao del Norte overlaid with topography, temperature, poverty level and sanitation data.

\section{Discussion}

\section{Relationship with schistosomiasis determinants and variables}

Humans contract SCH through exposure to Schistosoma cercariae in infested bodies of freshwater, where colonies of snail intermediate hosts are often found nearby. Development of $S$. japonicum will not proceed without colonies of $O$. hupensis quadrasi in the vicinity (CDC, 2013a). Temperature is an important determinant, both for the snail and the development of the parasite in its intermediate host (Zhou et al., 2008). Studies have shown that $S$. japonicum only develops in $O$. hupensis at temperatures higher than $15.4^{\circ} \mathrm{C}$, with the fastest development occurring at $30^{\circ} \mathrm{C}$ (Yang et al., 2006; Zhou et al., 2008). Land elevation may also affect $\mathrm{SCH}$ transmission, such that low-lying areas near bodies of freshwater may provide potential habitats for the snail intermediate host. Flooding has been reported to increase the area of potential snail habitats fivefold (Li et al., 2007) and may put more people at risk for exposure to water infested with cercaria, which may survive for up to 48 hours after being released by the snail intermediate host (Krauss et al., 2003). In China, the spread of Oncomelania snails to farmlands was found in eastern Dongting Lake a year after a flood which occurred in 1996 (Zhou et al.,

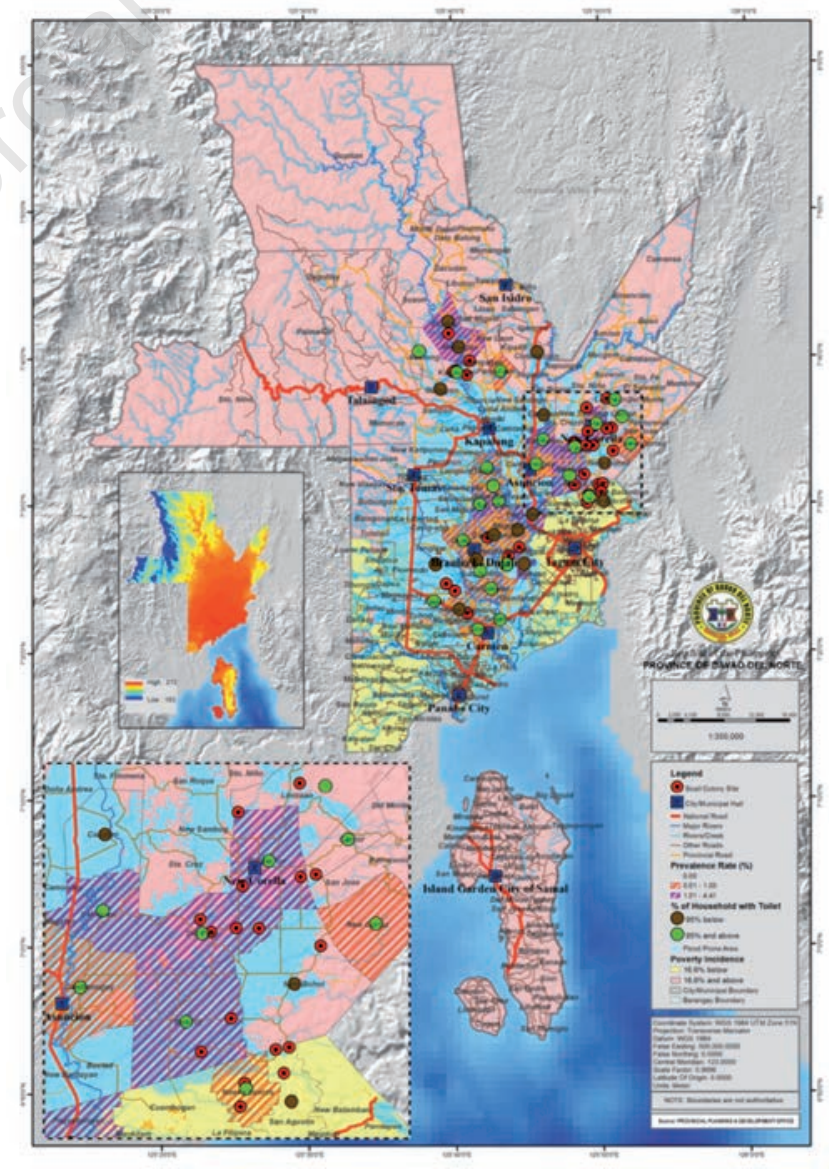

Figure 7. The schistosomiasis prevalence in Davao del Norte overlaid with topography, temperature and snail distribution data. 


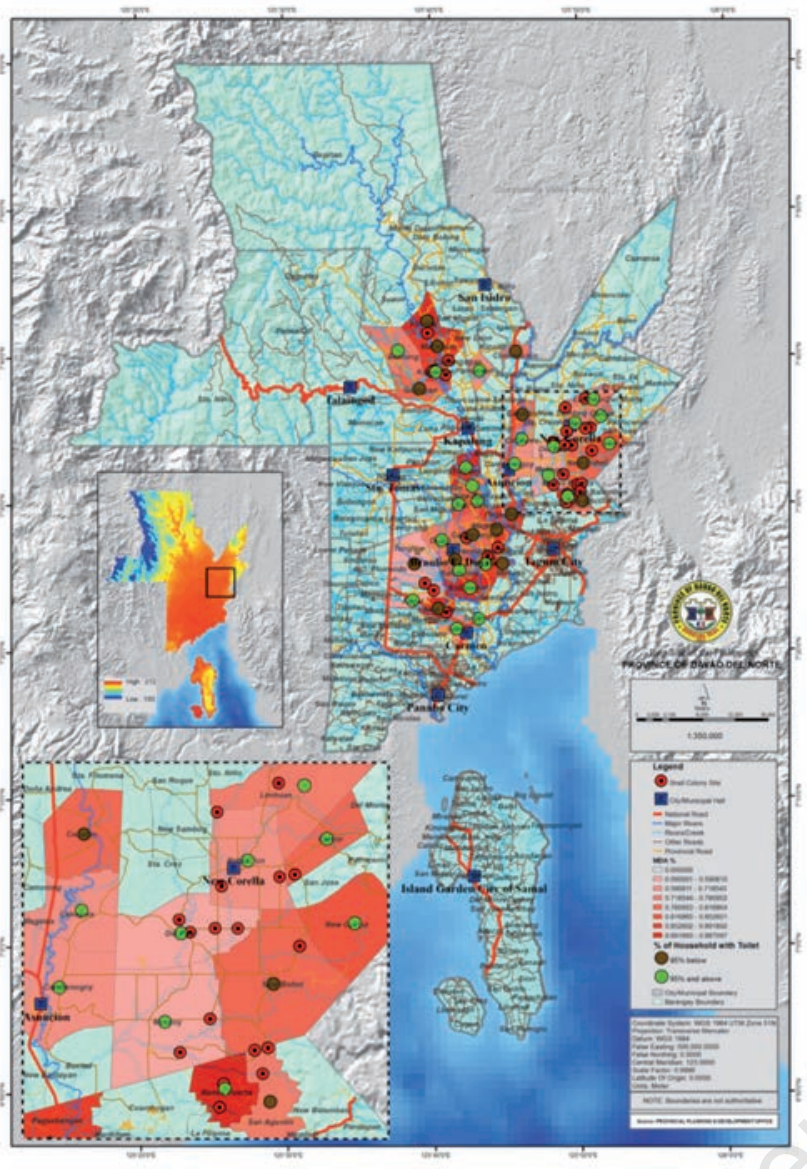

Figure 8. Mass drug administration coverage in Davao del Norte overlaid with topography, temperature, sanitation and the distribution of snail colonies data. Mass drug administration coverage is shown in proportion.

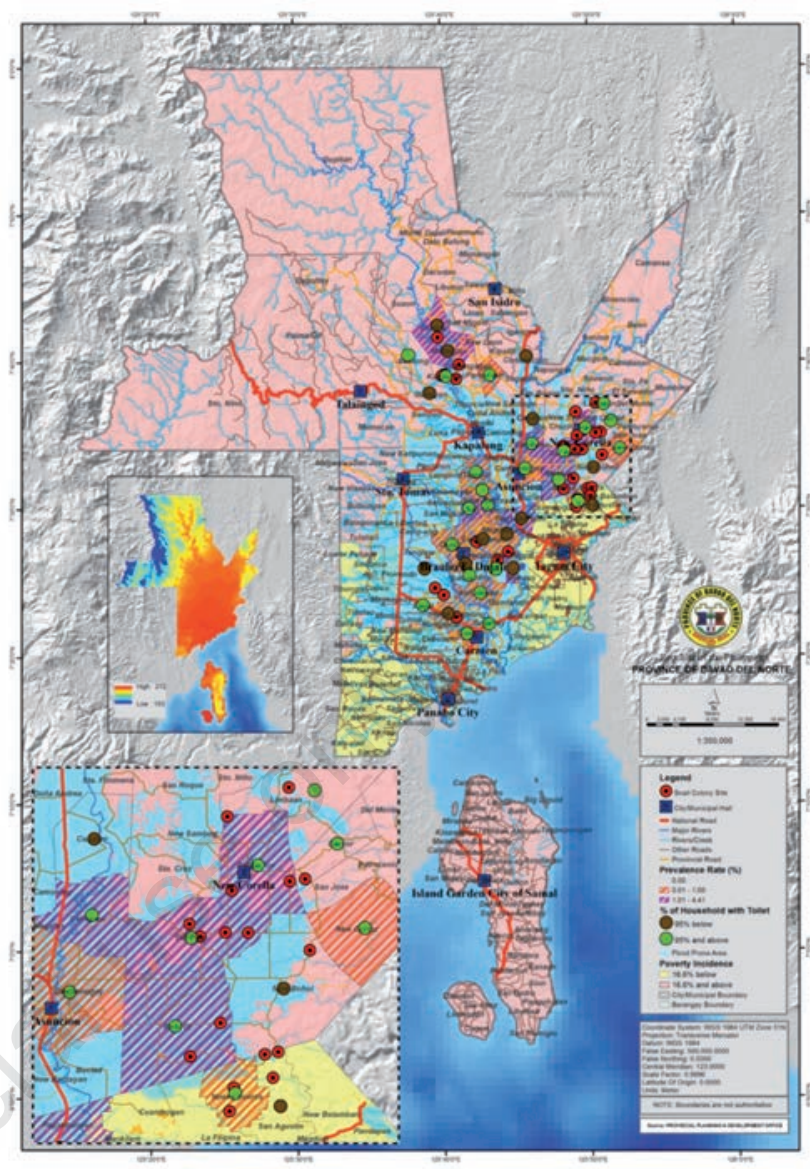

Figure 9. Map of Davao del Norte overlaid with the schistosomiasis determinants and variables.

Table 2. Determinants and variables/conditions for schistosomiasis in the municipalities and cities of Davao del Norte.

\begin{tabular}{|c|c|c|c|c|c|c|c|c|c|}
\hline $\begin{array}{l}\text { Determinant } \\
\text { SCH-favouring } \\
\text { condition }\end{array}$ & $\begin{array}{l}\text { Topo } \\
\text { Flood- } \\
\text { prone }\end{array}$ & $\begin{array}{l}\text { raphy } \\
\text { Irrigation } \\
\text { canals }\end{array}$ & $\begin{array}{c}\text { Land } \\
\text { use } \\
\text { Vegetation }\end{array}$ & $\begin{array}{c}\text { Temperature } \\
\left({ }^{\circ} \mathrm{C}\right) \\
15.4-30\end{array}$ & $\begin{array}{l}\text { Poverty } \\
\text { index } \\
>16.6 \%\end{array}$ & $\begin{array}{l}\text { Sanitation } \\
\text { index } \\
<95 \%\end{array}$ & $\begin{array}{c}\text { Intermediate } \\
\text { snail host } \\
\text { Colony } \\
\text { presence }\end{array}$ & $\begin{array}{l}\text { Reservoir } \\
\text { hosts } \\
\text { Presence } \\
\text { at location }\end{array}$ & $\begin{array}{c}\text { SCH } \\
\text { endemicity } \\
\text { Presence of } \\
\text { cases }\end{array}$ \\
\hline \multicolumn{10}{|c|}{ Municipality/City } \\
\hline Asuncion & $\checkmark$ & na* & $\checkmark$ & $\checkmark$ & $\checkmark$ & $x$ & $\checkmark$ & na* & $\checkmark$ \\
\hline B. Dujali & $\checkmark$ & na* & $\checkmark$ & $\checkmark$ & $\checkmark$ & $\checkmark$ & $\checkmark$ & na* & $\checkmark$ \\
\hline Carmen & $\checkmark$ & na* & $\checkmark$ & $\checkmark$ & $\checkmark$ & $x$ & $\checkmark$ & na* & $\checkmark$ \\
\hline IGACOS* & $\times$ & na* & $x$ & $\checkmark$ & $\checkmark$ & $x$ & $x$ & na* & $\times$ \\
\hline Kapalong & $\checkmark$ & na* & $\checkmark$ & $\checkmark$ & $\checkmark$ & $\checkmark$ & $\checkmark$ & na* & $\checkmark$ \\
\hline New Corella & $\checkmark$ & na* & $\checkmark$ & $\checkmark$ & $\checkmark$ & $x$ & $\checkmark$ & na* & $\checkmark$ \\
\hline Panabo City* & $\checkmark$ & na* & $\checkmark$ & $\checkmark$ & $\checkmark$ & $x$ & $x$ & na* & $x$ \\
\hline San Isidro* & $x$ & na* & $x$ & $\checkmark$ & $\checkmark$ & $x$ & $x$ & na* & $x$ \\
\hline Sto. Tomas & $\checkmark$ & na* & $\checkmark$ & $\checkmark$ & $\checkmark$ & $x$ & $\checkmark$ & na* & $\checkmark$ \\
\hline Tagum City & $\checkmark$ & na* & $\checkmark$ & $\checkmark$ & $x$ & $\checkmark$ & $x$ & na* & $\checkmark$ \\
\hline Talaingod* & $x$ & na* & $x$ & $\checkmark$ & $\checkmark$ & $x$ & $x$ & na* & $x$ \\
\hline
\end{tabular}

SCH, schistosomiasis; na, not available; IGACOS, Island Garden City of Samal. *Areas not known to be SCH-endemic. 
2001; Cai et al., 2005). Preventing floods may thus contribute to reduction of SCH transmission (Zhou et al., 2001). Establishment of irrigation systems in areas known to have snail colonies may also result in the introduction of snails into new areas (Peng et al., 2010). Although the temperature in Davao del Norte is suitable for SCH transmission; the GIS map showed that most SCH cases were reported in areas where snail colonies were identified, with exceptions of Cabaywa in Asuncion and Pagsabangan in Tagum City. The snail colony sites, however, may be grossly underestimated as they are based only on available data from malacological surveys conducted in sites where previous surveys have been conducted. A standardised protocol for malacological surveys including limited surveillance in barangays not known to be endemic should be developed and tested to help address this challenge. In addition to the identification of snail sites and colonies, assessment of snail densities may also be explored to facilitate a proper estimation of the SCH risk. It would be useful to also investigate the snail infection rates. SCH cases in Davao del Norte were mostly reported in low-lying areas, such as Carmen and Braulio Dujali, which are also flood-prone. Given the limitation in data on the intermediate host and the possibility of the spread of snail colonies through flooding, areas without identified snail colonies, but identified as flood-prone, such as Cabaywa in Asuncion and Pagsabangan in Tagum City, should be further investigated. Aside from snail intermediate hosts, carabaos, dogs and other animals are also of concern since these animals facilitate continuing transmission by serving as reservoir hosts (CDC, 2013a). Data on the distribution of these reservoir hosts, which are of limited availability in Davao del Norte LGU, is crucial. There is a need, therefore, to strengthen SCH surveillance to include data on reservoir hosts. This highlights the importance of engaging the veterinary public health sector in providing support not only in surveillance of reservoir hosts but also in control strategies targeting the intermediate and reservoir hosts (WHO, 2016).

The World Health Organization (WHO) recommends preventive chemotherapy as the strategy for SCH morbidity control. Annual MDA of praziquantel among high-risk groups will not only alleviate infected people from morbidity due to SCH but may also facilitate reduction in $\mathrm{SCH}$ transmission. Low MDA coverage rates, which were noted in municipalities in Davao del Norte, may contribute to increased $\mathrm{SCH}$ transmission since infected people, who did not benefit from preventive chemotherapy, may contaminate bodies of freshwater with Schistosoma ova especially if they practice open defecation (OD) (WHO, 2006). It is also important to note that MDA coverage may also vary among barangays or villages within the same municipality due to various reasons, such as cooperation of the barangay government. This highlights the importance of strengthening advocacy efforts and intersectoral collaboration to address the generally low MDA coverage rates, as well as the variations in MDA coverage rates in certain municipalities. While this study did not show a clear relationship between sanitation and $\mathrm{SCH}$ prevalence, the literature shows that high $\mathrm{SCH}$ prevalence may persist in areas with poor sanitation, where practice of OD may be rampant. Efforts to improve water, sanitation, and hygiene (WASH) may be strengthened in areas where OD prevails (Grimes et al., 2015). Studies have shown, however, that helminthiases still persist in some areas declared as OD-free (ODF) (Belizario et al., 2014, 2016). Thus, there may be a need to review and update the process of certifying ODF status. Validation of sanitation coverage by DOH and LGUs, with technical support from the academe, may be undertaken to reach this goal. The cur- rent protocol for declaring an area as ODF only focuses on human OD (UNICEF, 2016). In line with One Health (CDC, 2016) and considering that animal defecation also contributes to SCH transmission, there is a need to expand the current protocol to incorporate data on animal defecation. DOH and LGUs should also pursue zero OD (ZOD) in line with the National Sustainable Sanitation Plan of the DOH (Philippines Department of Health, 2010a, 2010b). Other SCH determinants include the social determinants of health, such as poverty. The GIS map showed that most of the endemic areas are characterised by poverty, which is consistent with available literature indicating that $\mathrm{SCH}$ is prevalent in impoverished areas (WHO, 2012). Morbidity, in turn, reduces productivity and perpetuates poverty (King, 2010). Improving SCH control and prevention may thus contribute to poverty alleviation and vice versa. While little may be done with non-modifiable determinants such as geography and climate, the GIS map may be used in identifying areas with a suitable environment and temperature range for the development of $S$. japonicum and O. hupensis quadrasi. This may be useful in disease surveillance and control, particularly in identifying areas at-risk or even predicting high-risk areas. Strengthening capacities of LGUs for passive case finding is recommended in areas identified by the GIS map as at-risk. Active case finding to complement passive case finding may also be conducted to provide a more accurate and updated data on $\mathrm{SCH}$.

The overlap of several determinants favourable for $\mathrm{SCH}$ endemicity highlights the importance of an innovative approach which may facilitate the utilisation of various data on SCH determinants to guide programme policy and planning for surveillance and effective control of SCH. Such approaches may find GIS to be important tool.

\section{Geographical information system in schistosomiasis prevention and control}

$\mathrm{SCH}$ transmission is affected by key factors, such as climatic suitability, spatial distribution of the intermediate host and human activities (Zhou et al., 2008; Peng et al., 2010; Chen et al., 2015). Implementation of effective prevention and control strategies necessitates accurate and up-to-date data on SCH determinants. Considering the focal distribution of $\mathrm{SCH}$, identification of patterns of the infection and its determinants are crucial (WHO, 1999; Ekpo et al., 2008). Although MDA may prove to be an effective strategy for morbidity control, it only targets the human morbidity aspect and does not address other factors contributing to transmission of the parasite. Mapping of the $\mathrm{SCH}$ distribution and its determinants would allow control programme managers to define the extent of the problem and use interventions accordingly (Ekpo et al., 2008). GIS has been used to further increase our understanding of the ecology and epidemiology of SCH in different settings (Cross et al., 1984; Malone et al., 1994; Bavia et al., 1999; Zhou et al., 2001; Brooker et al., 2002; Ekpo et al., 2008). Given that data on SCH determinants are collected by different local government offices, partner agencies and institutions, mapping of the presence and distribution of determinants through GIS may be useful in providing better analysis leading to facilitating policy formulation and strategic planning. The use of GIS allows the demonstration of conditions favouring transmission and the interplay of these determinants (Raso et al., 2009; Zhang et al., 2012; Chen et al., 2015). This is crucial in developing countries where resources are limited. Correctly applied, GIS contributes to evaluation of control programmes and review, since data visualisation in space and possibly also in time may help improve data utility (CDC, 2013b). 
Elimination of NTDs, as part of the SDGs (United Nations, 2016), warrants the use of innovative and sustainable approaches. Assessment of the progress of nations on the attainment of SDGs, which will be regularly reported to the United Nations, requires an organised and reliable system of data collection, processing, and analysis. GIS may serve as a tool for SCH surveillance and may be used to track the progress of control efforts through updating of data included in the GIS database.

\section{Role of local government units in schistosomiasis prevention and control}

In a decentralised health system, LGUs in the periphery play a crucial role in $\mathrm{SCH}$ prevention and control. With the devolution of the health system under the Local Government Code of 1991 (RA 7160), LGUs were granted autonomy and responsibility in the provision of health services, with technical support from the DOH through the regional offices (Philippines Department of Health, 1999). The LGUs serve as stewards of the local health system and are therefore expected to formulate and enforce local policies and ordinances in accordance with national policies and standards (WHO-WPRO, 2011). Data at the local level provided by LGUs may provide a clearer picture of the status of the infection, necessary in policy planning, formulation, and implementation for $\mathrm{SCH}$ prevention and control. Currently, there is no system for $\mathrm{SCH}$ surveillance which is institutionalised. Most data on $\mathrm{SCH}$ come from research or case reports of patients in the RHUs and government hospitals. The capacity of local health units (LHUs) to diagnose and manage $\mathrm{SCH}$ cases may likewise be enhanced. Monitoring of SCH by DOH and LGUs through sentinel surveillance, as well as capacity building of LHUs on diagnosis and case management of $\mathrm{SCH}$, may thus be considered.

Collaboration of different sectors at the local level is crucial in the formulation and implementation of efficient and effective health programs. Intersectoral collaboration may be facilitated through establishment of a committee, composed of representatives from various sectors. Regular meetings of the committee convened by the health sector may serve as a forum for sharing of information, review of SOPs, strategic planning, and identification of roles and responsibilities in the implementation of SCH prevention and control strategies.

\section{Limitations of the study}

The limitations of the study include the lack of barangay-level MDA coverage data for the other municipalities aside from Carmen and Braulio Dujali and lack of data on geographical location of reserve hosts and irrigation canals, which were both due to inability of the stakeholders to provide the data. We still included columns for this information in Table 2 to point the importance of access to these data. Another limitation was the lack of updated data on temperature in the Davao del Norte LGU and DOH RO XI. Further studies should address these limitations to generate available, up-to-date, and accurate evidence for policy formulation and planning. Inter-agency collaboration including not only the LGUs but also other government line agencies, such as DOH, DSWD and the NIA are expected to facilitate improvement in control and elimination of SCH and other endemic parasitic infections.

\section{Conclusions}

This study demonstrated the utility of GIS as a tool for SCH surveillance, particularly in characterising high-risk areas through visualising the role of the various SCH determinants and ecological variables. Utilising GIS as a tool for SCH surveillance, however, entails obtaining up-to-date and accurate spatial and temporal data. Thus, to maximise the use of GIS in SCH surveillance, there is a need to ensure availability and quality of data that entails updating and enhancing protocols and standard operating procedures (SOPs) for data collection. Development of an action plan for SCH prevention and control using data generated by the GIS could guide programme policy and planning toward more effective $\mathrm{SCH}$ control and prevention. There is also a need for validation of available data, as well as collection of unavailable data by the regional health office, local government units (LGUs), partner agencies, and institutions. Development of an action plan for $\mathrm{SCH}$ prevention and control using data generated by the GIS may guide program policy and planning toward $\mathrm{SCH}$ control and prevention.

\section{References}

Bavia ME, Hale LF, Malone JB, Braud DH, Shane SM, 1999. Geographic information systems and the environmental risk of schistosomiasis in Bahia, Brazil. Am J Trop Med Hyg 1999;60:566-72.

Belizario VY, Liwanag HJ, Naig JR, Chua PL, Madamba MI, Dahildahil RO, 2014. Parasitological and nutritional status of school-age and preschool-age children in four villages in Southern Leyte, Philippines: Lessons for monitoring the outcome of Community-Led Total Sanitation. Acta Trop 141:1624.

Belizario VY, Ng JV, Amarillo MLE, Delos Trinos JR, Reyes MR, Fudalan O, 2016. High burden of soil-transmitted helminthiases in preschool-age children in Masbate: A decade of implementation of the Integrated Helminth Control Program in the Philippines. Southeast Asian J Trop Med Public Health 47:667-79.

Brooker S, Hay SI, Tchuem Tchuenté LA, Ratard R, 2002. Using NOAA-AVHRR data to model human helminth distributions in planning disease control in Cameroon, West Africa. Photogram Eng Remote Sens 2002;68:175-9.

Cai KP, Hou XY, Li YY, 2005. Oncomelania snail survey in 41 areas of "breaking dikes or open sluice for waterstore" in Dongting Lake regions [in Chinese]. Chinese J Schistosomiasis Control 17:86-8.

Center for Disease Control, 2013a. Schistosomiasis. Center for Disease Control, Atlanta, GA, USA.

Center for Disease Control, 2013b. Using geographic information system in evaluation. Center for Disease Control, Atlanta, GA, USA.

Center for Disease Control, 2016. One health. Available from: https://www.cdc.gov/onehealth/

Chen YY, Huang XB, Xiao Y, Jiang Y, Shan XW, Zhang J, Cai SX, Liu JB, 2015. Spatial analysis of schistosomiasis in Hubei Province, China: a GIS-based analysis of schistosomiasis from 2009 to 2013. PLoS One 10:e0118362.

Cross ER, Sheffield C, Perrine R, Pazzaglia G, 1984. Prediction of areas of endemic schistosomiasis through use of discriminate 
analysis of environmental data. Mil Med 149:542-4.

Davao del Norte Provincial Environmental and Natural Resources, 2016. Available from: http://r11.denr.gov.ph/index.php/profiledavao-del-norte? showall $=1 \&$ limitstart $=$

Ekpo U, Mafiana C, Adeofun C, Solarin A, Idowi A, 2008. Geographical information system and predictive risk maps of urinary schistosomiasis in Ogun State, Nigeria. BMC Infect Dis 8:74.

Grimes JE, Croll D, Harrison WE, Utzinger J, Freeman MC, Templeton MR, 2015. The roles of water, sanitation and hygiene in reducing schistosomiasis: a review. ParasiteVectors 8:156.

Guimaraes R, Freitas C, Dutra L, Moura A, Amaral R, Drummond S, Scholte R, Carvalho O, 2008. Schistosomiasis risk estimation in Minas Gerais State, Brazil, using environmental data and GIS techniques. Acta Trop 108:234-41.

Hijmans RJ, Cameron SE, Parra JL, Jones PG, Jarvis A, 2005. Very high resolution interpolated climate surfaces for global land areas. Int J Climatol 25:1965-78.

Katanha A, Masocha V, 2014. Schistosomiasis an issue in floodprone area of DambakurimaWard 1, Muzarabani District of Zimbabwe. Int J Sci Res 3:646-50.

King CH, 2010. Parasites and poverty: the case of schistosomiasis. Acta Trop 113:95-104.

King CH, Dangerfield-Cha M, 2008. The unacknowledged impact of chronic schistosomiasis. Chronic Illness 4:65-79.

Krauss H, Weber A, Appel M, Enders B, Isenberg HD, Schiefer HG, Slenczka W, von Graevenitz, A, Zahner H, 2003. Zoonoses. Infectious diseases transmissible from animals to humans. Third Edition. ASM Press, Washington, DC, USA.

Leonardo LR, Crisostomo BA, Solon JAA, Rivera PT, Marcelo $\mathrm{AB}$, Villasper JM, 2007. Geographical information systems in health research and services delivery in the Philippines. Geospat Health 1:147-55.

Li YS, Raso G, Zhao ZY, He YK, Ellis MK, McManus DP, 2007. Large Water Management Projects and Schistosomiasis Control, Dongting Lake Region, China. Emerg Infect Dis 13:973-9.

Malone JB, Huh OK, Fehler DP, Wilson PA, Wilensky DE, Holmes RA, Elmagdoub AI, 1994. Temperature data from satellite imagery and the distribution of schistosomiasis in Egypt. Am J Trop Med Hyg 50:714-22.

Manyangadze T, Chimbari MJ, Gebreslasie M, Mukaratirwa S, 2015. Application of geo-spatial technology in schistosomiasis modelling in Africa: A review. Geospat Health 10:326.

McManus D, Gray D, Li Y, Feng Z, Williams G, Stewart D, Ladino J, Ross A, 2010. Schistosomiasis in the People's Republic of China: the Era of the Three Gorges Dam. Clin Microbiol Rev 23:442-66.

National Economic and Development Authority, 2013. Philippine Development Plan 2013-2016. Available from: www.neda. gov.ph/2013/10/21/philippine-development-plan-2011$2016 /+\& c d=3 \& h l=$ fil $\& c t=$ clnk $\& \mathrm{gl}=\mathrm{ph}$.

Peng WX, Tao B, Clements A, Jiang QL, Zhang ZJ, Zhou YB, 2010. Identifying high-risk areas of schistosomiasis and associated risk factors in the Poyang Lake region, China. Parasitology 137:1099-107.

Philippine Statistics Authority, 2013. Available from: http://www. nscb.gov.ph/activestats/psgc/regview.asp?region=11.

Philippine Atmospheric, Geophysical, and Astronomical Services Administration, 2016. Climate change in the Philippines.
Available from: https://web.pagasa.dost.gov.ph/index.php/climate-change-in-the-philippines\#climate-projections.

Philippines Department of Health, 1999. Health sector reform agenda: Philippines 1999 to 2004. Department of Health, Manila, Philippines.

Philippines Department of Health, 2007. Schistosomiasis control program. Available from: http://www.doh.gov.ph/schistosomiasis-control-program

Philippines Department of Health, 2009. Schistosomiasis control program briefer. Department of Health, Manila, Philippines.

Philippines Department of Health, 2010a. Administrative order 2010-0021 Sustainable Sanitation as a National Policy and a National Priority Program of the DOH. Department of Health, Manila, Philippines.

Philippines Department of Health, 2010b. National environmental health action plan. Available from: http://wedocs.unep.org/bitstream/handle/20.500.11822/18794/philippine_nehap_2010_2 013_07_07_10.pdf?sequence $=1 \&$ is Allowed $=\mathrm{y}$

Philippines Department of Health, 2015. Schistosomiasis. Available from: http://www.doh.gov.ph/schistosomiasiscomtrol-program

Raso G, Li Y, Zhao Z, Balen J, Williams GM, McManus DP, 2009. Spatial distribution of human Schistosoma japonicum infections in the Dongting Lake Region, China. PLoS One 4:e6947.

United Nations, 2016. Sustainable Development Goals. Available from: http://www.un.org/sustainabledevelopment/sustainabledevelopment-goals/

United Nations Children's Fund - India, 2016. Eliminating open defecation. Available from: http:/unicef.in/Whatwedo/11/ Eliminate-Open-Defecation

Wang Y, Zhuang D, 2015. Rapid monitoring and evaluation method of schistosomiasis based on spatial information. Int $\mathrm{J}$ Environ Res Public Health 12:15843-59.

WorldClim-Global Climate Data, 2017. WorldClim. Available from: http://www.worldclim.org

World Health Organization, 1994. Bench Aids for the diagnosis of intestinal parasites. World Health Organization, Geneva, Switzerland.

World Health Organization, 1999. Report on the WHO Informal Consultation on Schistosomiasis Control. WHO/CDS/CPC/ SIP/99.2, Geneva; 2-4 December 1999.

World Health Organization, 2006. Preventive chemotherapy in human helminthiasis coordinated use of antihelminthic drugs in control interventions: A manual for health professionals and program managers. World Health Organization, Geneva, Switzerland.

World Health Organization, 2012. Eliminating soil-transmitted helminthiases as a public health problem. World Health Organization, Geneva, Switzerland.

World Health Organization, 2016. Schistosomiasis. Available from: http://www.who.int/mediacentre/factsheets/fs115/en/

World Health Organization - Western Pacific Region, 2011. The Philippines Health System Review. Health Systems in Transition Vol. 1 No.2. World Health Organization - Western Pacific Region, Manila, Philippines.

Wu XH, Zhang SQ, Xu XJ, Huang YX, Steinmann P, Utzinger J, Wang TP, Xu J, Zheng J, Zhou XN, 2008. Effect of floods on the transmission of schistosomiasis in the Yangtze River Valley, People's Republic of China. Parasitol Int 57:271-6.

Yang GJ, Utzinger J, Sun LP, Hong QB, Vounatsou P, Tanner M, Zhou XN, 2006. Effect of temperature on the development of 
Schistosoma japonicum within Oncomelania hupensis, and hibernation of $O$. hupensis. Parasitol Res 100:695-700.

Zhang B, Zhang ZY, Xu DZ, Sun ZD, Zhou Y, Zhou XN, 2004. Application of landsat7-ETM + image in surveillance of snail distribution in mountain areas. Chin J Parasitic Dis Control 17:143-5.

Zhang Z, Zhu R, Ward MP, Xu W, Zhang L, Guo J, 2012. Longterm impact of the World Bank Loan Project for schistosomiasis control: a comparison of the spatial distribution of schistosomiasis risk in China. PLoS Negl Trop Dis 6:e1620.

Zhou XN, Malone JB, Kristensen TK, Bergquist NR, 2001.
Application of geographic information systems and remote sensing to schistosomiasis control in China. Acta Trop 79:97106.

Zhou XN, Yang GJ, Yang K, 2008. Potential impact of climate change on schistosomiasis transmission in China. Am J Trop Med Hyg 78:188-94.

Zhou XN, Yang GJ, Yang K, Wang XH, Hong QB, Sun LP, Malone JB, Kristensen TK, Bergquist NR, Utzinger J, 2008. Potential impact of climate change on schistosomiasis transmission in China. Am J Trop Med Hyg 78:188-94. 